Military Technical College

Kobry Elkobbah,

Cairo, Egypt

April 3-5,2018

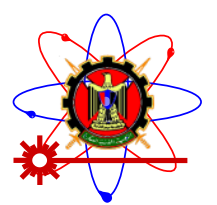

9th International Conference

on Mathematics and

Engineering Physics (ICMEP-9)

\title{
Measurement of enhanced emission from Titanium using nano- enhanced laser induced breakdown spectroscopy (NELIBS)
}

\author{
A. H. EL Farash ${ }^{\text {a }}$, A. M. EL Sherbini ${ }^{\text {b }}$, O. Helal ${ }^{\mathrm{a}}$, Ashraf F. El-Sherif ${ }^{\mathrm{a}}$ \\ ${ }^{a}$ Laser Photonics Research Center, Engineering Physics Department, \\ Military Technical College, Cairo, Egypt. \\ ${ }^{\mathrm{b}}$ Laboratory of Laser and New Materials, Faculty of Science, Cairo University, Giza, Egypt.
}

\begin{abstract}
Detection of material ingredients is the main goal of the Laser-Induced Breakdown Spectroscopy (LIBS) technique. However, the light signal from the very little elemental concentration is small enough to produce large errors (relatively large limit of detection LOD). In order to enhance the light signal (spectral radiance) from the very small impurity concentrations, we suggested the addition of drops of gold nanoparticles (NPs) solution on the surface of metallic titanium in what is called nanoparticle-enhanced laser induced breakdown spectroscopy (NELIBS). The radiation from $\mathrm{Nd}$ :YAG pulsed laser at $1064 \mathrm{~nm}$ was used to irradiate the surface of titanium before and after the addition of nano-gold layer at an energy range from $60 \mathrm{~mJ}$ to $200 \mathrm{~mJ}$ in an open air. An echelle type spectrograph equipped with time controlled ICCD camera was used to resolve the emission spectrum from plasma. Ti I spectral lines at wavelengths of 453.32 and $498.17 \mathrm{~nm}$ were identified with recorded enhancement factors up to $\times 20$, and this was achieved at the lower laser fluence of $4 \mathrm{~J} / \mathrm{cm}^{2}$. Strong reduction in the plasma ignition threshold by factor of 40 from the pure bulk titanium to nano-gold coated titanium was achieved, with similar reduction of limit of detection LOD. A theoretical work is in advance to explain the origin of the enhanced emission.
\end{abstract}

Keywords: LIBS, Nanoparticles, Titanium, Enhancement, plasma, Laser fluence, nano-gold.

\section{INTRODUCTION}

Laser-Induced Breakdown Spectroscopy technique (LIBS) is classified as one of the most versatile technique among the other spectrochemical analytical techniques as being based on precise plasma spectroscopy science. At first, the analyzed material is converted into plasma state upon irradiation with high peak power pulsed lasers (with minimum irradiance level of $10^{7} \mathrm{~W} / \mathrm{cm}^{2}$ ). It was assumed that the light emitted from this plasma is sufficiently influenced by the elemental structure of the sample as well as the concentration of the different sample ingredients. A wealth of information can be gained upon precise analysis of the light emitted from this pulsed plasma. Therefore, It was 


\section{Military Technical College \\ Kobry Elkobbah, \\ Cairo, Egypt \\ April 3-5,2018}

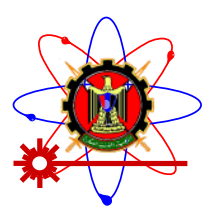

recommended in many of spectrochemical analytical applications [1-3], e.g., biochemistry [4] space exploration [5], environmental and forensic sciences [6]. It contain many advantages over other conventional techniques because of its non-destructive nature, high degree of reliability, real-time results and finally, almost-there is no sample preparation [7]. However, it have a certain shortage in detecting the very limited elemental concentrations (lower than $\sim 5 \mathrm{ppm}$ ) of trace elements inside the examined sample as the spectral line intensity of the prominent lines decreased to values that is comparable to the noise level (i.e. small signal to noise-SNR lower than three) [8]. The limit of detection (LOD) was taken as the main parameter that can tell about the lower limit of detection of rarefied concentrations. It depends on two main factors, the signal height and the background signal. One cannot be avoided which is the background level (noise) since it is naturally arises from universe; on the other hand, one can work on the best way to increase the signal height arises from the very small concentrations.

A sincere efforts were provided to overcome this problem utilizing different techniques which includes the use of double-pulse laser [9-11], ultra short laser pulses [12,13] or a blended technique $[14,15]$, but these techniques depend on raising the laser abilities that require a new laser source which need to change the experimental set up as well as increasing the overall cost.

Not very recently, a modified LIBS as known as Nanoparticle-Enhanced lased induced breakdown spectroscopy (NELIBS) was supposed to enhance the signal height intensity while it takes the advantage of the daily progress of nanotechnology utilizing its unique thermal and physical properties to increase the detection sensitivity (reduce LOD) $[16,17]$ and reserves the advantages of normal LIBS.

In this technique one should use very small additives on the form of a thin layer of some noble metals put on the surface of the analyzed alloy. It was noticed that this additive is greatly enhances the optical signal arising from the bulk material [18]. Until recently there is no tied physical theory about this enhancement of the optical signals. Rather, some explanations was provided due to some authors [ Alessendro.. ] that are almost depends on certain ad-hoc assumptions based on practical work.

In this article, we shall briefly discuss the results of the observed enhancement of the Ti I-lines at wavelengths of 453.32 and $498.17 \mathrm{~nm}$, before and after addition of thin layer of nano gold particles to the surface of bulk titanium target in what is called NELIBS. The process is repeated at different incident laser energies until threshold of plasma ignition was reach. A comparison to simple model was carried with nice agreement. 
Military Technical College

Kobry Elkobbah,

Cairo, Egypt

April 3-5,2018

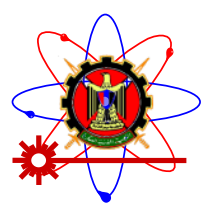

9th International Conference

on Mathematics and

Engineering Physics (ICMEP-9)

\section{EXPERIMENTAL DETAILS}

The utilized experimental setup shown in Fig. 1 is the same as in refs [18, 19]. It comprises Nd-YAG laser (type Quantel-Brilliant B) working at the fundamental wavelength of $1064 \mathrm{~nm}$ and two other harmonics at 532 and $355 \mathrm{~nm}$ with output laser energy of $30 \pm 3,100 \pm 4$ and $370 \pm 5 \mathrm{~mJ}$ per pulse at the wavelengths of 355,532 and $1064 \mathrm{~nm}$, respectively. The laser spot size was adjusted at the target surface by changing the distance from focusing lens to target $95 \pm 1 \mathrm{~mm}$ and was measured at the position of the target using a special thermal paper (supplied with Quantel $囚$ ) found almost of circular shape of radius $0.7 \pm 0.05 \mathrm{~mm}$ at the laser wavelength $1064 \mathrm{~nm}$. In order to avoid the laser focusing lens chromatic aberration, the plasma ignition in open air was observed first and then the target was positioned at distances lower than this distance. This routine granted that the plasma emission is originated from the target rather than ambient air. The light from the plasmas was collected using $400 \mathrm{~mm}$ diameter optical fiber $(\mathrm{NA}=0.22)$ to the entrance hole of the SE200- Echelle type spectrograph (optical resolution of $0.02 \mathrm{~nm}$ per pixel with instrumental bandwidth of $0.2 \mathrm{~nm}$ on the average).

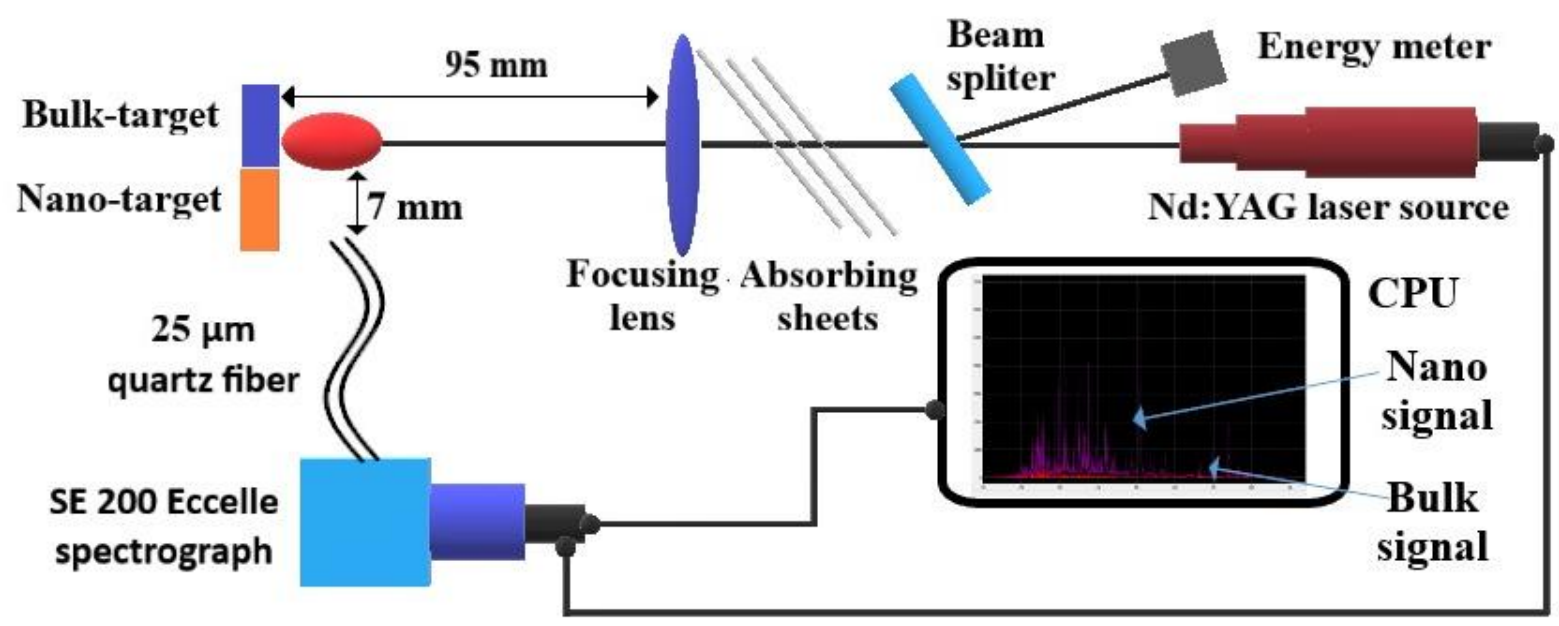

Fig. 1 Experimental setup

The resolved spectra was acquired using a fast response ICCD camera (Andor- iStar DH734-18F) and the data control was carried using KestrelSpec ${ }^{\circledR} 3.96$ software with resolution of $0.02 \mathrm{~nm}$ per pixel of size $196 \mu \mathrm{m}^{2}$. The optical fiber was positioned at distance of $7 \pm 1 \mathrm{~mm}$ from the laser-plasma axis using a precise xyz-holder. The gold nanomaterial solution that purchased from "Nanotech CO" -prepared by chemical reduction method with concentration of $200 \mu \mathrm{g} / \mathrm{mL}$ in water- was deposited on the titanium metallic surface. A standard micro-pipette is used to drop $10 \mu \mathrm{L}$ on the surface and then the solution was evaporated to leave the gold NPs plated on the titanium surface. The 
Military Technical College

Kobry Elkobbah,

Cairo, Egypt

April 3-5,2018

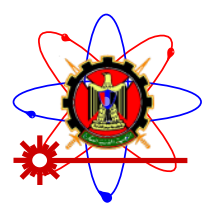

9th International Conference

on Mathematics and

Engineering Physics (ICMEP-9)

nanoparticles have spherical shapes with diameter (D 20nm) measured using TEM as shown in Fig. 2 and no distortions was observed. Both of the delay and gate times were adjusted to the levels of 1 $\mu$ s and $3 \mu$ s respectively. The delay and gate times are chosen after many trails until we get the strongest observed line emission from the plasma with the minimum of background continuum radiation resulted from free-free and free-bound transitions. The background stray lights during experiment was measured and subtracted and with the help of ICCD-KestrelSpec ${ }^{\circ}$ software. The noise level resulted from the detection electronics was measured across the whole wavelength region $(250-850 \mathrm{~nm})$ and was found as $20 \pm 7$ counts. The incident laser energy at each laser shot was measured utilizing a quartz beam splitter and the reflected part (4\%) is incident in an absolutely calibrated power-meter (Ophier model 1z02165). The laser pulse shape was measured using 25 ps fast response photodiode in conjunction with digital storage CRO (type Tektronix model TDS 1012) and was found stable at level of $5 \pm 1 \mathrm{~ns}$. The laser energy was tuned in the range of laser energies using a set of calibrated neutral density filters. The absolute sensitivity of the whole spectrograph, camera and optical fiber was carried using DH2000-CAL lamp supplied by Ocean optics (SN037990037).

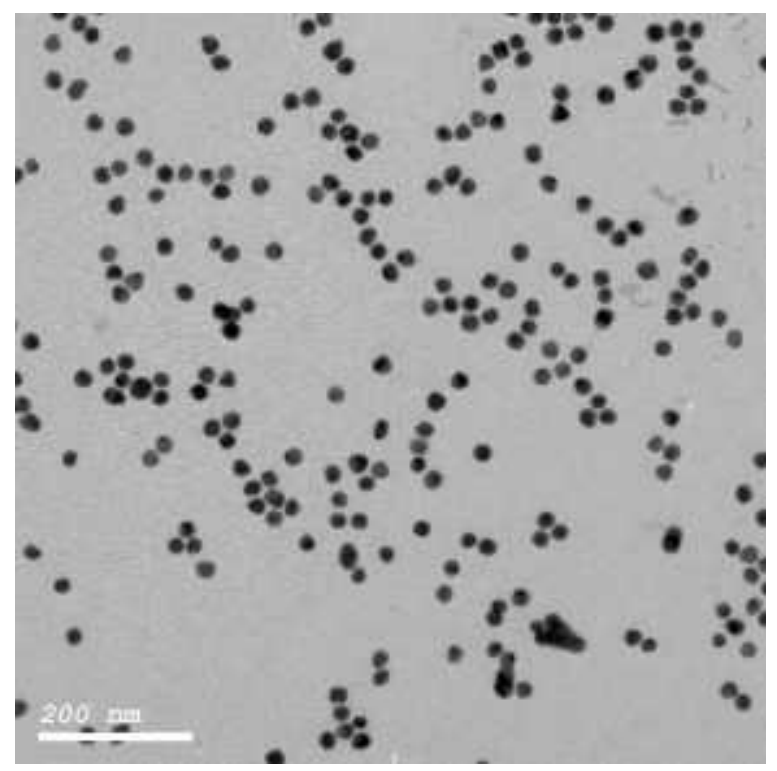

Fig. 2 Transmission electron microscope (TEM) of the gold-nanoparticles 
Military Technical College

Kobry Elkobbah,

Cairo, Egypt

April 3-5,2018 9th International Conference

on Mathematics and

Engineering Physics (ICMEP-9)

\section{RESULTS AND DISCUSSION}

Fig. 3 shows the spectral line intensity at the two prominent Ti I lines at wavelengths 453.32, 498.17 $\mathrm{nm}$ as recorded from both of the bulk titanium target (solid lines) and the one coated with gold nanoparticles (dashed lines). An apparent increase (enhancement) is obvious just after addition of the nano-gold thin sheet. It is worth noting that, the spectral radiance enhancement factor has a greater value at the smaller laser fluence of $5.24 \mathrm{~J} / \mathrm{cm}^{2}$ and vice versa at the larger fluence $(9.7$ $\mathrm{J} / \mathrm{cm}^{2}$ ). 
Military Technical College

Kobry Elkobbah,

Cairo, Egypt

April 3-5,2018

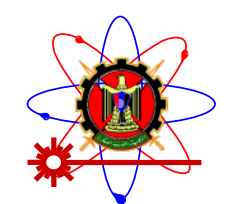

9th International Conference

on Mathematics and

Engineering Physics (ICMEP-9)

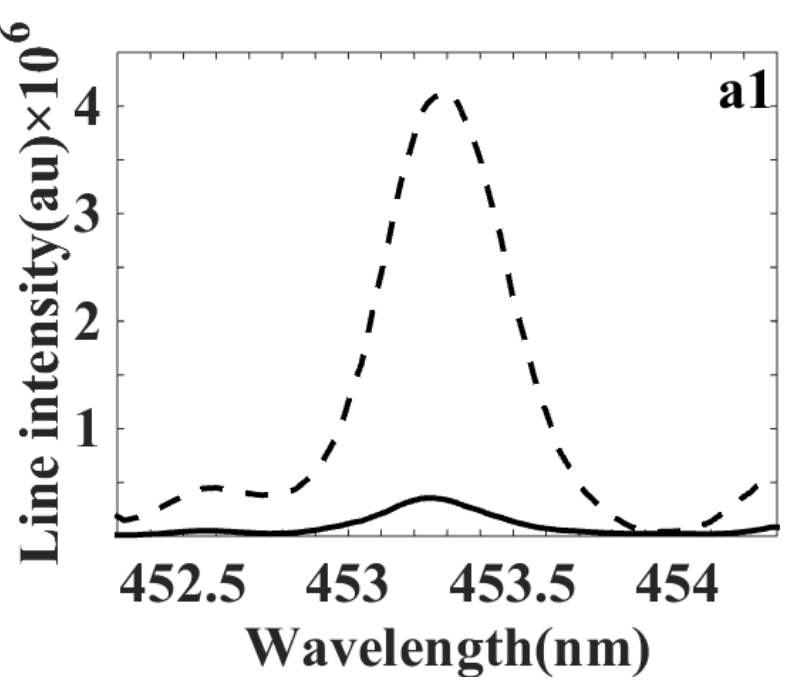

$\lambda=453.32 \mathrm{~nm}$

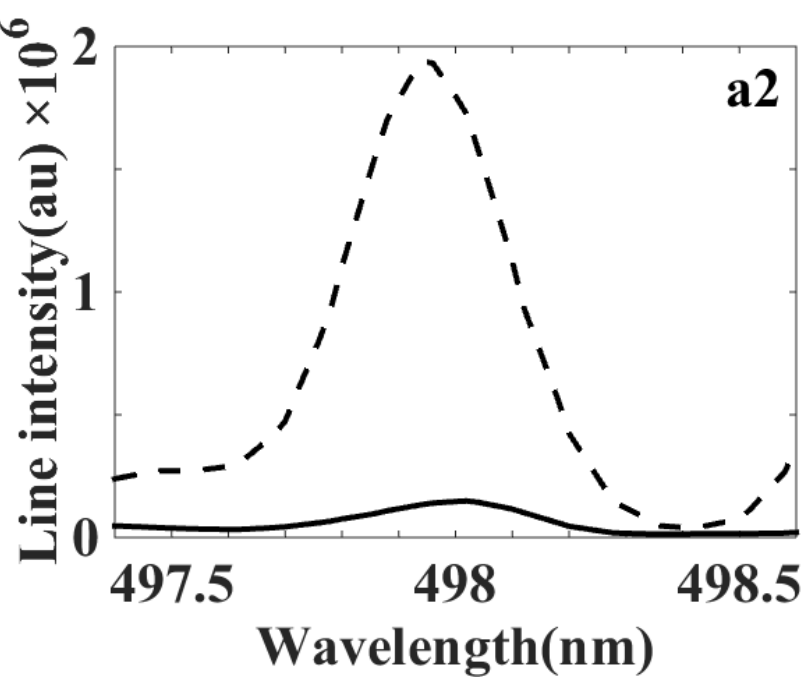

$\lambda=498.17 \mathrm{~nm}$

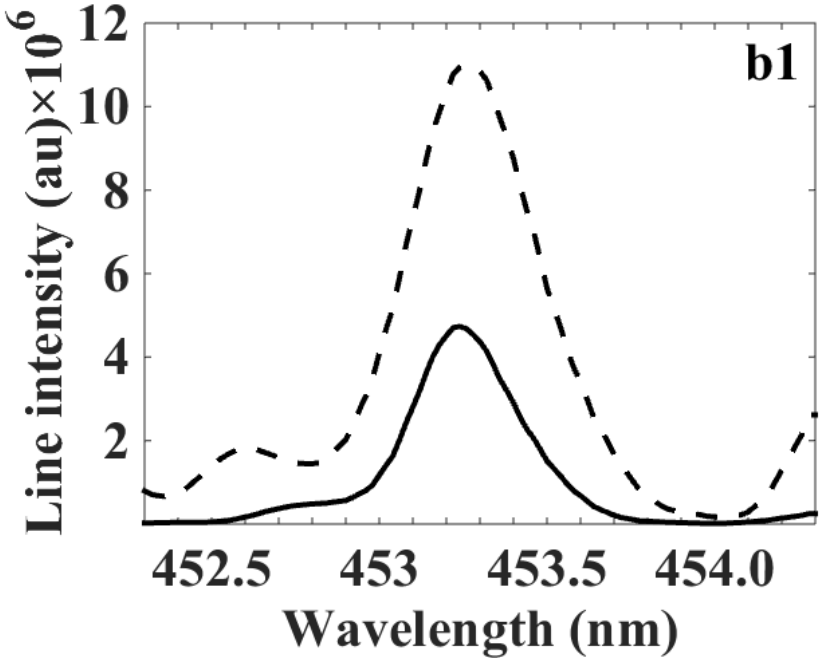

$\lambda=453.32 \mathrm{~nm}$

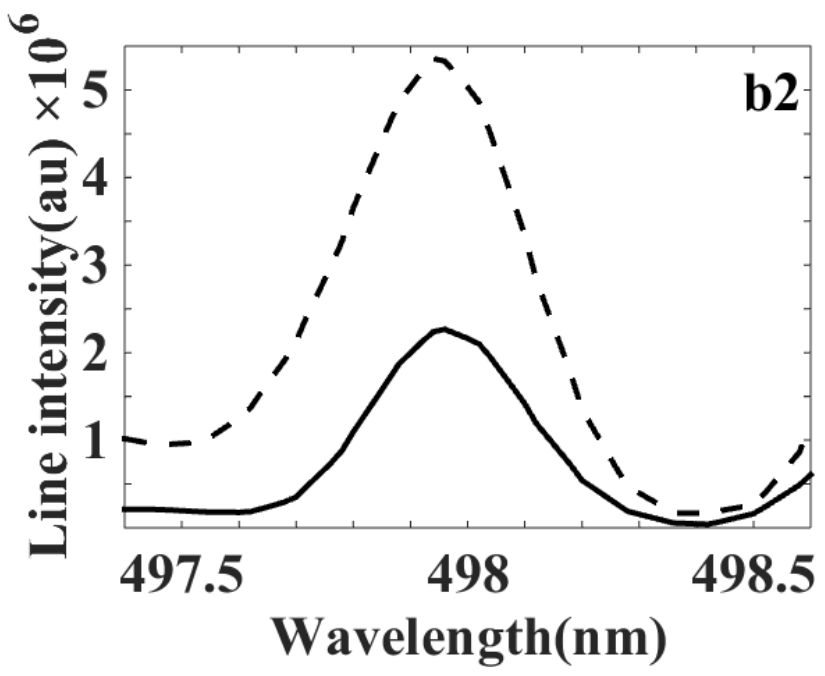

$\lambda=498.17 \mathrm{~nm}$

Fig. 3 spectral line intensity enhancement at laser fluences (a1, a2) $5.24 \mathrm{~J} / \mathrm{cm}^{2}$, (b1, b2) 9.7 $\mathrm{J} / \mathrm{cm}^{2}$ at wavelengths $(453.4,498.17) \mathrm{nm}$

The variation of the enhancement factor of the two spectral lines at 453.4 and $498.17 \mathrm{~nm}$ with laser fluence is presented at Fig. 4 in the range from $20 \mathrm{~J} / \mathrm{cm}^{2}$ down to $4 \mathrm{~J} / \mathrm{cm}^{2}$. An obvious decrease in the signal enhancement factor with laser fluence until reaching a value close to one at the highest 
Military Technical College

Kobry Elkobbah,

Cairo, Egypt

April 3-5,2018

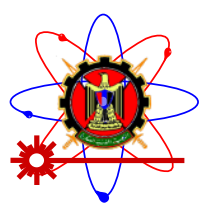

9th International Conference

on Mathematics and

Engineering Physics (ICMEP-9)

fluence of $12.9 \mathrm{~J} / \mathrm{cm}^{2}$ is shown in Fig. $4(\mathrm{a}, \mathrm{b})$ at the Ti I wavelengths of 453.32 and $498.17 \mathrm{~nm}$, respectively.
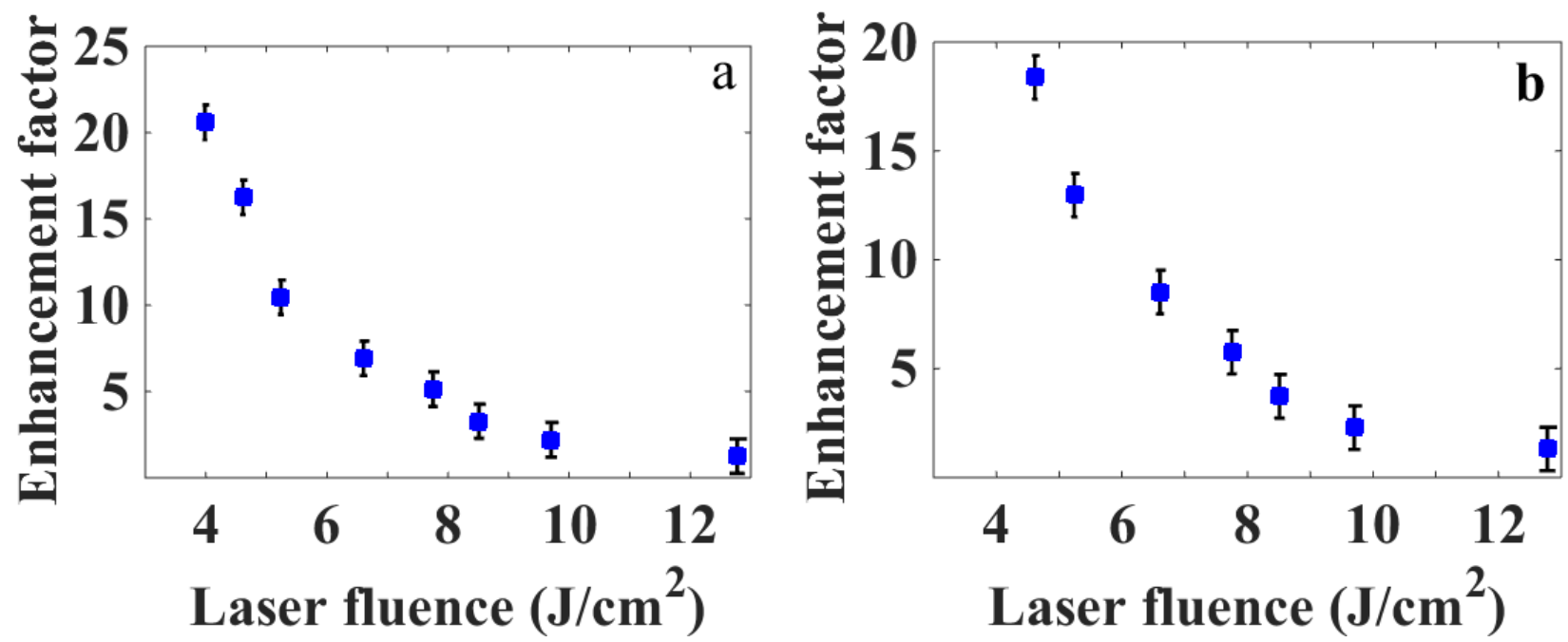

Fig. 4 Variation of enhancement factor at different laser fluence at different Ti I lines (a) $\lambda=$ $453.32 \mathrm{~nm}$, (b) $\lambda=498.17 \mathrm{~nm}$

In order to investigate physically the reason lie behind this enhancement decrease with increasing laser fluence, a plot of the signal height arises from both of bulk Ti (lower points) in comparison to the nano-gold-covered Ti (upper points) is presented at Fig. 5 (a, b). The laser energy was detuned using a set of calibrated absorbing glass sheets and the signals heights were recorded. A backward extrapolation to the laser threshold fluence from both targets leads to different threshold values as shown. It was found that the plasma ignition threshold playing an important role in plasma creation in Laser-Induced Breakdown Spectroscopy as explored at refs. [20, 21]. 
Military Technical College

Kobry Elkobbah,

Cairo, Egypt

April 3-5,2018 9th International Conference

on Mathematics and

Engineering Physics (ICMEP-9) $\mathbf{a}$

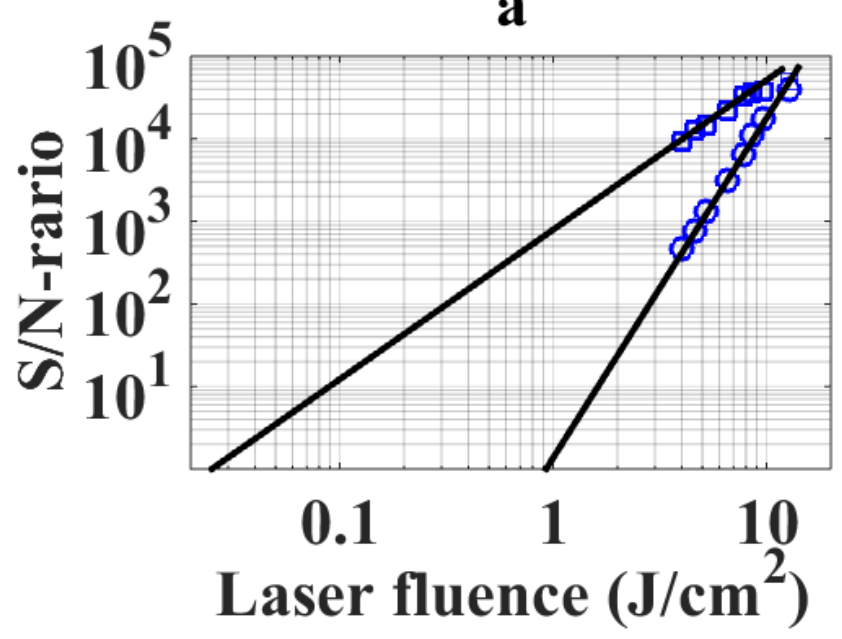

b

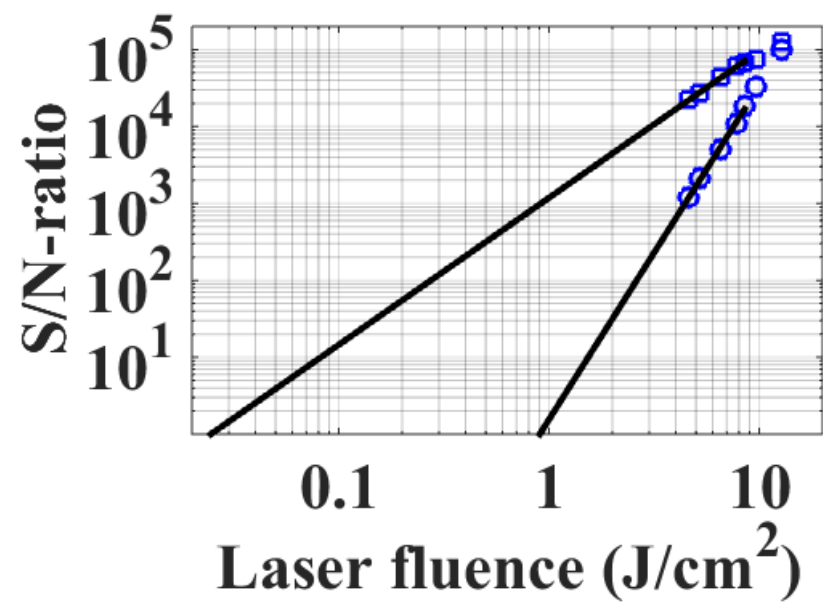

Fig. 5 Signal-to-noise ratio of Ti I lines at (a) $453.32 \mathrm{~nm}$, (b) $498.17 \mathrm{~nm}$ versus laser fluence of both bulk titanium (circles) and nano-gold enhanced titanium (squares).

On the other hand, from the theoretical point of view, for titanium bulk-based plasma the laser fluence threshold $\varphi_{t h}$ can be calculated in terms of material density $\rho$, latent heat of vaporization $\mathrm{L}_{\mathrm{v}}$, ionization angry $\mathrm{E}_{\mathrm{i}}$, thermal conduction length $l_{T}$, and laser wavelength $\lambda$ from Eq. (1) [8]

$\varphi_{t h}=\left(\rho L_{v}+\frac{8 \pi^{2} m_{e} \varepsilon_{0} c^{2}}{e^{2}} \frac{E_{i}}{\lambda^{2}}\right) l_{T}=\varphi_{t h}=\left(\rho L_{v}+2.235 \times 10^{15} \frac{E_{i}}{\lambda^{2}}\right) l_{T}$

Where

$l_{T}=\sqrt{K_{T} \tau_{l} / \rho C_{p}}$

Where $\mathrm{K}_{\mathrm{T}}$ is the thermal conductivity, $\mathrm{C}_{\mathrm{p}}$ is the heat capacity, and $\tau_{l}$ is the laser pulse duration.

Table 1 Values of titanium and laser properties

\begin{tabular}{llll} 
& Property & Value & Unit \\
\hline \multirow{4}{*}{$\begin{array}{l}\text { Target material } \\
\text { (Titanium) }\end{array}$} & Density $(\rho)[22]$ & 4500 & $\mathrm{Kg} / \mathrm{m}^{3}$ \\
\cline { 2 - 4 } & Latent heat of vaporization $\left(\mathrm{L}_{\mathrm{v}}\right)[23]$ & 8.88 & $\mathrm{MJ} / \mathrm{Kg}$ \\
\cline { 2 - 4 } & Ionization angry $\left(\mathrm{E}_{\mathrm{i}}\right)[24]$ & 6.83 & $\mathrm{Joule}$ \\
\cline { 2 - 4 } & Thermal conductivity $\left(\mathrm{K}_{\mathrm{T}}\right)[25]$ & 21.9 & $\mathrm{~W} / \mathrm{m} \cdot \mathrm{K}$ \\
\cline { 2 - 4 } Laser source & Heat capacity $\left(\mathrm{C}_{\mathrm{p}}\right)[25]$ & 523 & $\mathrm{~J} / \mathrm{Kg} \cdot \mathrm{K}$ \\
\hline \multirow{2}{*}{ Wavelength $(\lambda)$} & 1064 & $\mathrm{~nm}$ \\
\cline { 2 - 4 } & Pulse duration $\left(\tau_{l}\right)$ & 5 & $\mathrm{~nm}$
\end{tabular}




\section{Military Technical College \\ Kobry Elkobbah, \\ Cairo, Egypt \\ April 3-5,2018}

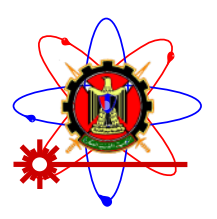

The theoretical value of the laser fluence threshold in case of bulk-based titanium is calculated by substitution with the titanium and laser values as given in Table 1 , and found to be $0.91 \mathrm{~J} / \mathrm{cm}^{2}$ which is very close to the experimental result that is equal $0.9 \pm 0.1 \mathrm{~J} / \mathrm{cm}^{2}$ and also experimentally, the laser fluence threshold is found to be $0.025 \pm 0.005 \mathrm{~J} / \mathrm{cm}^{2}$ in gold-deposited titanium as shown in Fig. 5 for both spectral lines at 453.4 and $498 \mathrm{~nm}$. It is worth noting that, these measured differences in plasma ignition threshold from bulk to nano-deposited gold value is lower by a factor come on 40 than the bulky one.

This means that the plasma ignition threshold from the gold-coated titanium starts at much smaller values than the bulk one, and hence the signal enhancement factor appears very large at the lower irradiance values. Probably, because the nano particles has a large absorption to the incident laser light, and hence, these particles are fragmented into much smaller ones carrying a sufficient energy to break the interatomic forces of the titanium solid and leading to much lower vaporization [ Alessendro..], while an effort should be carried in order to put a satisfactory physical explanation.

\section{CONCLUSION}

The recorded data that was analyzed in this paper proved beyond a shadow of doubt that depositing gold nanoparticles on a titanium metallic surface enhance the emitted plasma signal intensity (LOD reduced) in LIBS by a good factor that enable us to detect elements even if it is represented with little concentration in a compound as the spectral radiance was enhanced. The enhancement factor was calculated at different laser fluence values and the result was the lower the laser fluence the larger the enhancement factor. For bulk-based titanium, the Laser fluence threshold was calculated theoretically and experimentally and found to be approximately equal in magnitude. But, for nanogold coated titanium, the laser fluence threshold was found experimentally to be lower than pure bulk titanium. This results reduces the need of laser sources with ultrashort pulses. More studies would be made for different bulk materials and nanoparticles solutions at different wavelengths and nanoparticle sizes to get an empirical forum for the laser fluence threshold of the materials deposited with nanoparticles.

\section{REFERENCES}

[1] R. S. Harmon, R. E. Russo, and R. R. Hark, "Applications of laser-induced breakdown spectroscopy for geochemical and environmental analysis: A comprehensive review," Spectrochimica Acta Part B: Atomic Spectroscopy, vol. 87, pp. 11-26, 2013. 
Military Technical College

Kobry Elkobbah,

Cairo, Egypt

April 3-5,2018

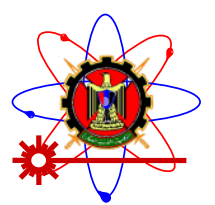

[2] D. Rusak, B. Castle, B. Smith, and J. Winefordner, "Fundamentals and applications of laser-induced breakdown spectroscopy," Critical Reviews in Analytical Chemistry, vol. 27, no. 4, pp. 257-290, 1997.

[3] O. Samek et al., "Application of laser-induced breakdown spectroscopy to in situ analysis of liquid samples," Optical Engineering, vol. 39, no. 8, pp. 2248-2263, 2000.

[4] A. C. Samuels, F. C. DeLucia, K. L. McNesby, and A. W. Miziolek, "Laser-induced breakdown spectroscopy of bacterial spores, molds, pollens, and protein: initial studies of discrimination potential," Applied optics, vol. 42, no. 30, pp. 6205-6209, 2003.

[5] R. Wiens et al., "Pre-flight calibration and initial data processing for the ChemCam laserinduced breakdown spectroscopy instrument on the Mars Science Laboratory rover," Spectrochimica Acta Part B: Atomic Spectroscopy, vol. 82, pp. 1-27, 2013.

[6] M. Z. Martin et al., "High resolution applications of laser-induced breakdown spectroscopy for environmental and forensic applications," Spectrochimica Acta Part B: Atomic Spectroscopy, vol. 62, no. 12, pp. 1426-1432, 2007.

[7] A. M. El-Sherbini, M. M. Hagras, H. H. Farag, and M. Rizk, "Diagnosis and classification of liver cancer using LIBS technique and artificial neural network," International Journal of Science and Research, vol. 4, pp. 1153-1158, 2015.

[8] A. M. EL Sherbini and C. G. Parigger, "Wavelength dependency and threshold measurements for nanoparticle-enhanced laser-induced breakdown spectroscopy," Spectrochimica Acta Part B: Atomic Spectroscopy, vol. 116, pp. 8-15, 2016.

[9] V. Babushok, F. DeLucia, J. Gottfried, C. Munson, and A. Miziolek, "Double pulse laser ablation and plasma: Laser induced breakdown spectroscopy signal enhancement," Spectrochimica Acta Part B: Atomic Spectroscopy, vol. 61, no. 9, pp. 999-1014, 2006.

[10] D. W. Hahn and N. Omenetto, "Laser-induced breakdown spectroscopy (LIBS), part II: review of instrumental and methodological approaches to material analysis and applications to different fields," Applied spectroscopy, vol. 66, no. 4, pp. 347-419, 2012.

[11] R. Sanginés and H. Sobral, "Time resolved study of the emission enhancement mechanisms in orthogonal double-pulse laser-induced breakdown spectroscopy," Spectrochimica Acta Part B: Atomic Spectroscopy, vol. 88, pp. 150-155, 2013.

[12] S. M. Angel, D. N. Stratis, K. L. Eland, T. Lai, M. A. Berg, and D. M. Gold, "LIBS using dual-and ultra-short laser pulses," Fresenius' journal of analytical chemistry, vol. 369, no. 3, pp. 320-327, 2001.

[13] D. Du, X. Liu, G. Korn, J. Squier, and G. Mourou, "Laser- induced breakdown by impact ionization in $\mathrm{SiO} 2$ with pulse widths from $7 \mathrm{~ns}$ to $150 \mathrm{fs,"} \mathrm{Applied} \mathrm{physics} \mathrm{letters,} \mathrm{vol.} \mathrm{64,}$ no. 23, pp. 3071-3073, 1994. 
Military Technical College

Kobry Elkobbah,

Cairo, Egypt

April 3-5,2018

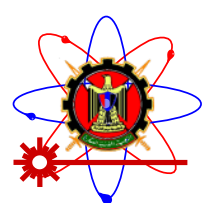

[14] J. Scaffidi, W. Pearman, M. Lawrence, J. C. Carter, B. W. Colston, and S. M. Angel, "Spatial and temporal dependence of interspark interactions in femtosecond-nanosecond dual-pulse laser-induced breakdown spectroscopy," Applied optics, vol. 43, no. 27, pp. 5243-5250, 2004.

[15] J. Scaffidi et al., "Dual-pulse laser-induced breakdown spectroscopy with combinations of femtosecond and nanosecond laser pulses," Applied optics, vol. 42, no. 30, pp. 6099-6106, 2003.

[16] A. De Giacomo, R. Gaudiuso, C. Koral, M. Dell'Aglio, and O. De Pascale, "Nanoparticleenhanced laser-induced breakdown spectroscopy of metallic samples," Analytical chemistry, vol. 85, no. 21, pp. 10180-10187, 2013.

[17] A. De Giacomo, R. Gaudiuso, C. Koral, M. Dell'Aglio, and O. De Pascale, "Nanoparticle Enhanced Laser Induced Breakdown Spectroscopy: Effect of nanoparticles deposited on sample surface on laser ablation and plasma emission," Spectrochimica Acta Part B: Atomic Spectroscopy, vol. 98, pp. 19-27, 2014.

[18] A. M. El Sherbini, A.-N. M. Aboulfotouh, F. F. Rashid, S. H. Allam, A. El Dakrouri, and T. M. El Sherbini, "Observed enhancement in LIBS signals from nano vs. bulk $\mathrm{ZnO}$ targets: comparative study of plasma parameters," World Journal of Nano Science and Engineering, vol. 2, no. 04, p. 181, 2012.

[19] A. El Sherbini, A. A. Galil, S. Allam, and T. M. El Sherbini, "Nanomaterials induced plasma spectroscopy," in Journal of Physics: Conference Series, 2014, vol. 548, no. 1, p. 012031: IOP Publishing.

[20] L. Cabalin and J. Laserna, "Experimental determination of laser induced breakdown thresholds of metals under nanosecond Q-switched laser operation," Spectrochimica Acta Part B: Atomic Spectroscopy, vol. 53, no. 5, pp. 723-730, 1998.

[21] B. N. Chichkov, C. Momma, S. Nolte, F. Von Alvensleben, and A. Tünnermann, "Femtosecond, picosecond and nanosecond laser ablation of solids," Applied Physics A, vol. 63, no. 2, pp. 109-115, 1996.

[22] R. G. Munro, "Material properties of titanium diboride," Journal of Research of the National Institute of Standards and Technology, vol. 105, no. 5, p. 709, 2000.

[23] Y. Zhang, J. R. Evans, and S. Yang, "Corrected values for boiling points and enthalpies of vaporization of elements in handbooks," Journal of Chemical \& Engineering Data, vol. 56, no. 2, pp. 328-337, 2011.

[24] P. Forsberg, "The spectrum and term system of neutral titanium, Ti I," Physica Scripta, vol. 44, no. 5, p. 446, 1991.

[25] D. W. Rankin, "CRC handbook of chemistry and physics, edited by David R. Lide," ed: Taylor \& Francis, 2009. 